University of Nebraska - Lincoln

DigitalCommons@University of Nebraska - Lincoln

\title{
The Use of Landmarks by Clark's Nutcrackers: First Tests of a New Model
}

\author{
Alan Kamil \\ University of Nebraska - Lincoln, akamil1@unl.edu \\ Aleida J. Goodyear \\ University of Nebraska - Lincoln, ajgoodyear@hotmail.com \\ Ken Cheng \\ Macquarie University
}

Follow this and additional works at: https://digitalcommons.unl.edu/bioscibehavior

Part of the Behavior and Ethology Commons

Kamil, Alan; Goodyear, Aleida J.; and Cheng, Ken, "The Use of Landmarks by Clark's Nutcrackers: First Tests of a New Model" (2001). Papers in Behavior and Biological Sciences. 10.

https://digitalcommons.unl.edu/bioscibehavior/10

This Article is brought to you for free and open access by the Papers in the Biological Sciences at DigitalCommons@University of Nebraska - Lincoln. It has been accepted for inclusion in Papers in Behavior and Biological Sciences by an authorized administrator of DigitalCommons@University of Nebraska - Lincoln. 


\title{
The Use of Landmarks by Clark's Nutcrackers: First Tests of a New Model
}

\author{
Alan C. Kamil and Aleida J. Goodyear \\ (University of Nebraska, Lincoln, USA) \\ Ken Cheng \\ (Macquarie University, Sydney, Australia)
}

\begin{abstract}
Animals use many different mechanisms to navigate in space. The characteristics of the mechanism employed are usually well-suited to the demands of each particular navigational problem. For example, desert ants navigating in a relatively featureless environment use path integration, birds homing or migrating over long distances use compasses of various sorts, salmon returning to their natal stream home on olfactory cues. The study of navigation requires the study of many different taxa confronting different problems. One interesting case involves scatter-hoarding species that use memory to relocate their hidden food. Such animals face the problem of remembering many locations simultaneously. Clark's nutcrackers (Nucifraga columbiana) are an excellent example, and this paper considers their possible use of multiple bearings from landmarks.
\end{abstract}

\section{KEY WORDS}

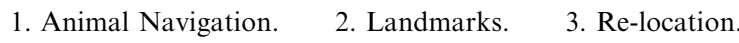

1. INTRODUCTION. Animals use many different mechanisms to navigate in space. The characteristics of the mechanism employed is usually well-suited to the demands of each particular navigational problem. For example, desert ants navigating in a relatively featureless environment use path integration (Muller and Wehner, 1988). Birds homing or migrating over long distances use compasses of various sorts (Dyer, 1998). Salmon returning to their natal stream home on olfactory cues (Hasler, 1960). The study of navigation requires the study of many different taxa confronting different problems.

One interesting case involves scatter-hoarding species that use memory to re-locate their hidden food. Such animals face the problem of remembering many locations simultaneously. Clark's nutcrackers (Nucifraga columbiana) are an excellent example. Every fall they cache tens of thousands of pine seeds in thousands of different locations. Evidence from both field (Tomback, 1980; Vander Wall and Hutchins, 1983) and laboratory (Kamil and Balda, 1985) demonstrates that nutcrackers use spatial memory to relocate their caches, that this memory is both long-lasting (Balda and Kamil, 1992) and dynamic, and that it changes contents as caches are emptied (Kamil et al., 1993). It is clear from several experiments that the relationship between the location of the cache and of surrounding landmarks is critical (Vander Wall, 1982; Balda and Turek, 1984). Furthermore, the birds often use landmarks that are 
located relatively far from the goal site (Gould-Beierle and Kamil, 1999). These characteristics make Clark's nutcracker an excellent species on which to base a study into the use of landmarks during navigation.

Kamil, Balda and Good (1999) analyzed the movement patterns of nutcrackers during caching and recovery. When recovering a cache, the nutcrackers tended to approach from the same direction they had used when creating the cache. However, the birds also often used a different approach direction. Most importantly, accuracy was equally high in either case. This shows that the birds do not use a fixed path. In addition, since the appearance of the site differs when approached from different directions, this suggests that they do not use a 'snapshot' of the scene, in contrast to honey bees, who typically face in a stereotyped direction when using landmarks (Cheng, 2000; Collett, 1996).

The results of several studies indicate that the nutcrackers use multiple landmarks to navigate. For example, when Vander Wall (1980) displaced the landmarks in one part of his aviary, the birds appeared to use both the shifted and un-shifted set. In another case, Basil (1993) trained nutcrackers to find a goal location defined by an array of nine landmarks. The birds were then able to find the goal when tested with various three-landmark subsets of the array. This use of multiple landmarks is somewhat puzzling. It only requires knowledge of the distance and direction from the cache site to a single landmark to define the goal position. If nutcrackers remember the locations of many cache sites, they could reduce the memory load by minimizing the amount they remembered about each individual site.

To summarize what is known about navigation and cache recovery by Clark's nutcrackers: they need to remember the locations of many cache sites simultaneously, they do not use path integration, fixed paths or snapshots as a primary mechanism, they do use multiple landmarks, often located relatively far from the site, to relocate caches and they are also known to use directional information. Clock shifts sometimes affect the accuracy of cache recovery in nutcrackers (Wiltschko et al., 1999) and other seed caching birds (Wiltschko and Balda, 1989; Duff et al., 1998). But a basic question remains unanswered. What information do they encode that allows them to recognize a site when they try to relocate it?

One hint of an answer comes from data collected by Kamil and Jones (1997). Nutcrackers were trained to find a seed that was always buried halfway between two landmarks when the distance between the landmarks varied. The problem of locating the midpoint is a two part problem. The line connecting the landmarks must be found, a problem of estimating direction. Then the correct point on the line must be found, a problem of estimating distance. Kamil and Jones were able to partition search error into these two components by measuring error parallel and perpendicular to the line connecting the landmarks. This produced a surprising result. Both types of error increased as the distance between the landmarks (and therefore the distance from the goal location to either landmark) increased, but the distance error increased more rapidly than direction error. This result clearly implied that when the distance between a goal and landmarks was large, directional information would produce more accurate search than distance information.

However, that stills leaves the puzzle of the use of multiple landmarks. It only requires two bearings, the direction from the goal to each of two landmarks, to define a location. But nutcrackers seem to track more than two landmarks. Why should this be the case? Kamil and Cheng (2001) proposed that the explanation may be compass 
error. Using only two bearings may be insufficient to pinpoint a discrete location such as a cache. If there is error in the compass, searching at the intersection of the two bearings will not result in finding the goal. Furthermore, there will be no information available about where to search next. A computer simulation showed that additional bearings increased search accuracy when there was a one or two percent error in the compass (Kamil and Cheng, 2001). These considerations led Kamil and Cheng to propose the multiple bearings hypothesis, that nutcrackers encode the bearing from the goal to multiple landmarks whenever the distance between the goal and nearest landmark is relatively great.

This hypothesis is not completely novel (e.g., see Gallistel, 1990 - Chapter 3; and Baker, 1982). However, Kamil and Cheng more thoroughly explored the implications and predictions of this idea than had earlier workers. One of the attractions of the multiple bearings model is that it makes a set of extremely specific predictions.

2. METHODS. In order to test some of these predictions, we trained five nutcrackers to find a seed whose location was defined by an array of four landmarks. The landmarks were located 60, 75, 90 and $105 \mathrm{~cm}$ from the goal, arranged so that all of the goal-landmark lines met at right angles. These goal-landmark distances were selected because Jones and Kamil (1997) found that distance error began to exceed direction error when goal-landmark distances were greater than $45 \mathrm{~cm}$. After the birds had learned to find the buried seed with all four landmarks present, we proceeded to train them with all 15 possible combinations of the landmarks. That is they were tested extensively with all four landmarks, with each of the four ways of presenting three of the landmarks, with each of the six ways of presenting a pair of landmarks and with each of the four landmarks by itself. This testing continued for 600 trials, generating a substantial data set that allowed tests of four predictions of the multiple bearings model.

Every trial was videotaped through a camera mounted on the ceiling above the test area. We then used video tracking software to determine the Cartestian (X,Y) position of each dig and of the goal. These coordinates were then used to calculate the mean distance of each dig from the goal for each session based on the average of the absolute distance of each of the first five digs to the goal location. In order to rule out the use of olfactory cues, one out of every five test trials were conducted with no seed present. On these 120 no-seed trials, the birds were allowed to make forty probes in the substrate. As search accuracy during these no-seed trials was almost exactly the same as during trials with seed present, data from both trial types were pooled for analysis.

\section{RESULTS.}

3.1 Prediction 1. Accuracy should improve as the number of landmarks present increases. This prediction was clearly confirmed; distance error increased significantly as the number of landmarks present decreased $(\mathrm{p}<0.01$; see Figure 1). However, it must be regarded as a weak test of the model because of the variation in goallandmark distances. That is, the greater the number of landmarks present, the more likely it was that one of the landmarks in the array was very close to the goal, which had a strong effect on search accuracy.

3.2 Prediction 2. Distance error will increase more rapidly as goal-landmark distance increases than will direction error. Although this was observed by Kamil and 


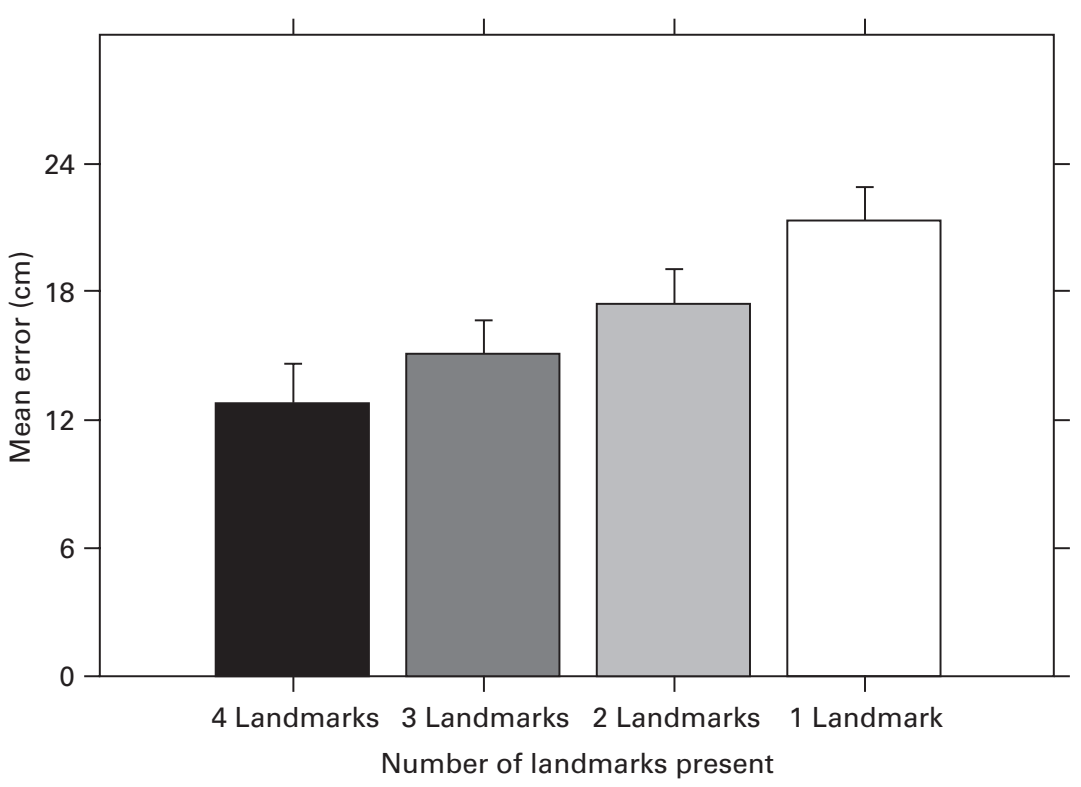

Figure 1. Mean search error as a function of the number of landmarks present.

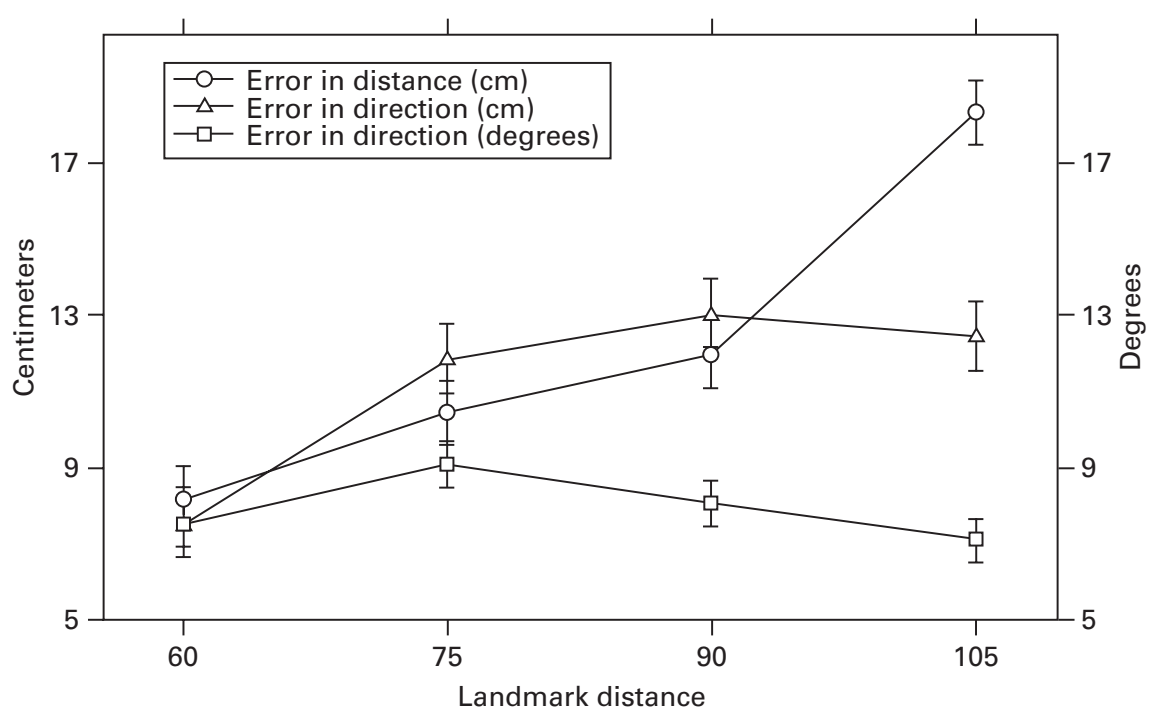

Figure 2. Data from trials in which only a single landmark was present, for search error measured in $\mathrm{cm}$ and partitioned into distance and direction components, and for the direction component measured in degrees.

Jones $(1997,2000)$, these experiments involved arrays of two landmarks, and the prediction needed confirmation when only a single landmark was present. To test this prediction, we compared search accuracy for the four single landmark conditions. The results were as predicted (see Figure 2). When linear regression was used to calculate the slopes of each function, they were significantly different $(p<0 \cdot 02)$. 

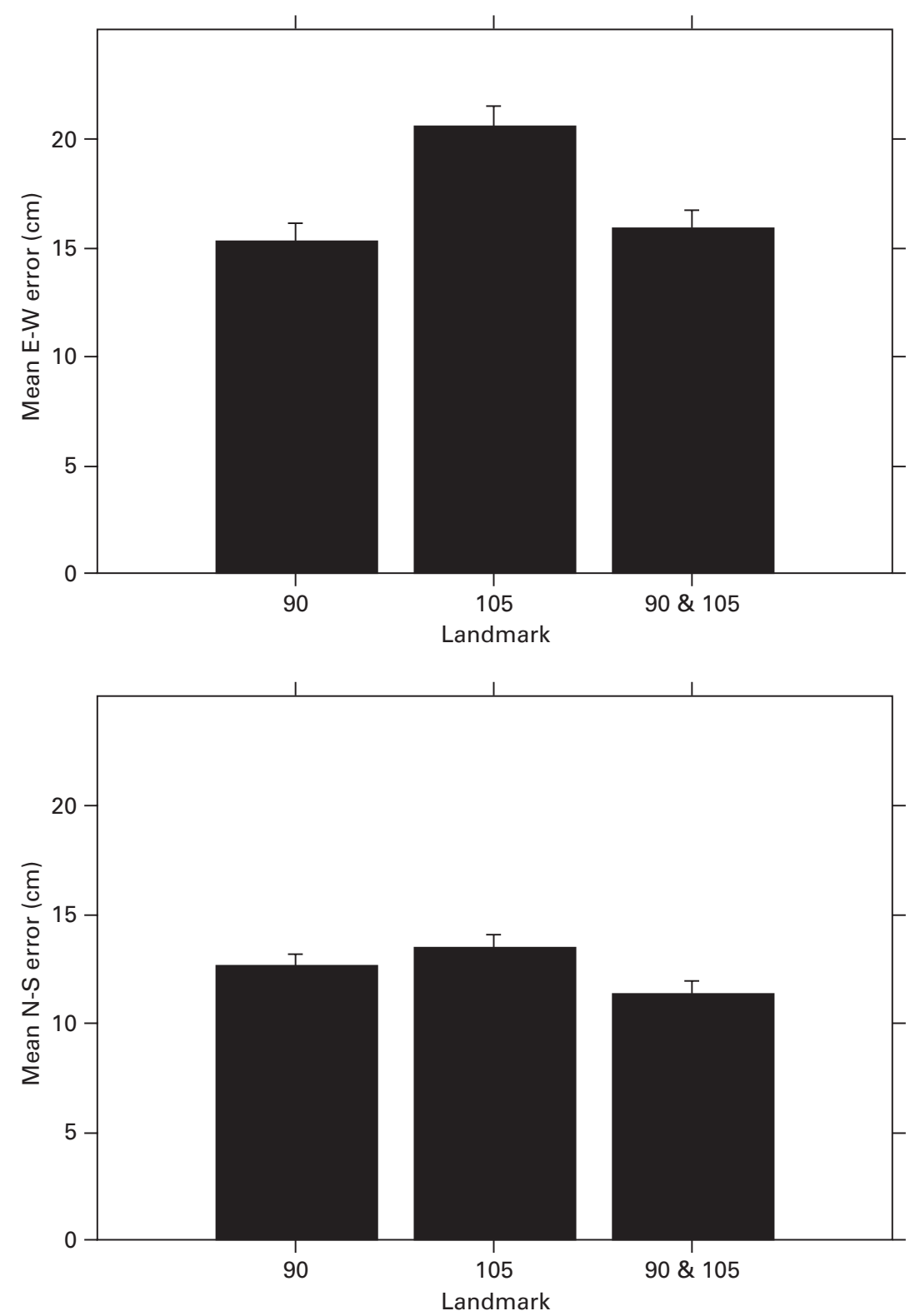

Figure 3. Mean error in each axis for presentations of the 90 and $105 \mathrm{~cm}$ landmarks presented individually and together. 3a: Error in the EW axis. 3b: Error in the NS axis.

3.3 Prediction 3. That direction error calculated in degrees will be constant at all goal-landmark distances. Kamil and Cheng (2001) argued that distance error and direction error were the result of different processes. Distance error is an example of a psychophysical phenomenon known as Weber's Law. When an organism assesses a quantitative attribute of an object, the error in the estimate increases as the magnitude of the attribute increases, as is the case with estimating goal-landmark distance. But when estimating direction, the attribute does not increase in quantity. 
The compass direction or angle being estimated is the same regardless of goallandmark distance. Therefore when direction error is calculated in degrees rather than centimetres, it should be constant at all goal-landmark distances. This prediction was confirmed. The slope of direction error in degrees as a function of goal-landmark distance did not differ significantly from zero $(\mathrm{p}>0 \cdot 20$ (see Figure 2$)$ ).

3.4 Prediction 4. When landmarks are sufficiently distant from the goal, the distribution of error in the single landmark tests can be used to predict error when two adjacent landmarks are present. Consider the case of two landmarks, one north and the other east of the goal. Distance error will be greater than direction error. Therefore, when only the north landmark is present, there should be more error in the NS axis than in the EW axis and vice versa when only the east landmark is present. Now when both landmarks are present, the model predicts that the bird will use directional information from each landmark. Thus we expect error in the NS axis to be equal to NS error when only the east landmark was present and EW error to be equal to that found when only the north landmark was present.

Only a partial test of this prediction was possible because most of the landmarks were too close to the goal to produce the requisite difference between distance and direction error. However, for the one case where this prediction could be tested, with the 90 and $105 \mathrm{~cm}$ landmarks, the data were largely in accord with the prediction. The $90 \mathrm{~cm}$ axis was located north of the goal and the $105 \mathrm{~cm}$ landmark was located east of the goal. Thus when both landmarks were present, we predict that error in the EW axis should be equal to that in the EW axis when only the $90 \mathrm{~cm}$ landmark was present. Error in the NS axis with both landmarks present should be equal to error in the NS axis when only the $105 \mathrm{~cm}$ landmark was present. This was clearly true for EW error (Figure 3a). In the case of NS error, the error with both landmarks present was less than predicted (Figure $3 b$ ).

4. DISCUSSION. The results of this preliminary experiment were limited because most of the goal-landmark distances were too small to result in distance error that was greater than direction error. We can only speculate that this contrast with the results of Kamil and Jones (1997) is due to differences between the halfway task and the procedures of the current experiment. Despite this shortcoming, some of the predictions of the multiple bearings hypothesis could be tested. Search error declined as the number of landmarks present increased, direction error increased more slowly than distance error as goal-landmark distance increased and direction error was constant when measured in degrees. However, much more research is needed to evaluate fully the multiple bearings hypothesis. We have constructed a large, circular test room and are currently training birds with a set of longer goal-landmark distances. Hopefully, this experiment will produce more conclusive data to test the multiple bearings hypothesis in the near future.

\section{REFERENCES}

Baker, R. (1982). Migration: Paths through time and space. London: Hodder and Stoughton. Balda, R. P. and Turek, R. J. (1984). The cache-recovery system as an example of memory capabilities in Clark's nutcracker. In: Animal Cognition (Ed. by Roitblat, H. L., Bever, T. G. and Terrace, H. S.), pp. 513-532. Hillsdale, NJ: Lawrence Erlbaum Associates.

Balda, R. P. and Kamil, A. C. (1992). Long-term spatial memory in Clark's nutcracker, Nucifraga columbiana. Animal Behaviour 44, 761-769. 
Basil, J. A. (1993). Neuroanatomical and Behavioral Correlates of Spatial Memory in Clark's Nutcrackers. Unpublished dissertation. University of Massachusetts, $221 \mathrm{pp}$.

Collett, T. S. (1996). Insect navigation en route to the goal: Multiple strategies for the use of landmarks. The Journal of Experimental Biology 199, 227-235.

Duff, S. J., Brownlie, L. A., Sherry, D. F. and Sangster, M. (1998). Sun compass and landmark orientation by black-capped chickadees (Parus atricapillus). Journal of Experimental Psychology: Animal Behavior processes 24, 243-253.

Dyer, F. C. (1994). Spatial cognition and navigation in insects. In: L. Real (Ed.), Behavioral Mechanisms in Evolutionary Ecology (pp. 66-98). Chicago: University of Chicago Press.

Gallistel, C. R. (1990). The Organization of Learning. Cambridge, MA, M. I. T. Press.

Hasler, A. D. (1960). Guideposts of migrating fishes. Science 132, 785-792.

Gould-Beierle, K. L. and Kamil, A. C. (1999). The role of proximity in landmark use by Clark's nutcrackers. Animal Behaviour 58, 477-488.

Kamil, A. C., Balda, R. P. and Good, S. (1999). Patterns of movement and orientation during caching and recovery by Clark's nutcrackers (Nucifraga columbiana). Animal Behaviour 57, 1327-1335.

Kamil, A. C. and Balda, R. P. (1985). Cache recovery and spatial memory in Clark's nutcrackers (Nucifraga columbiana). Journal of Experimental Psychology: Animal Behavior Processes 11, 95-111.

Kamil, A. C., Balda, R. P., Olson, D. J. and Good, S. (1993). Revisits to emptied cache sites by Clark's nutcrackers (Nucifraga columbiana): A puzzle revisited. Animal Behaviour 45, 241-252.

Kamil, A. C. and Jones, J. E. (2000). Geometric rule learning by Clark's nutcrackers (Nucifraga columbiana). Journal of Experimental Psychology: Animal Behavior Processes 26, 439-453.

Kamil, A. C. and Jones, J. E. (1997). The seed-caching corvid Clark's nutcracker learns geometric relationships among landmarks. Nature 390, 276-279.

Kamil, A. C. and Cheng, K. (2001). Way-finding and landmarks: the multiple-bearings hypothesis. The Journal of Experimental Biology 204, 103-113.

Muller, M. and Wehner, R. (1988). Path integration in desert ants, Cataglyphis fortis. Proceedings of the National Academy of Sciences 85, 5287-5290.

Tomback, D. F. (1980). How nutcrackers find their seed stores. Condor 82, 10-19.

Vander Wall, S. B. (1982). An experimental analysis of cache recovery in Clark's nutcracker. Animal Behaviour 30, 84-94.

Vander Wall, S. B. and Hutchins, H. E. (1983). Dependence of Clark's nutcracker (Nucifraga columbiana) on conifer seeds during the postfledgling period. Canadian Field Naturalist 97, 208-214.

Wiltschko, W. and Balda, R. P. (1989). Sun compass orientation in seed-caching scrub jays. Journal of Comparative Physiology A 164, 717-721.

Wiltschko, W., Balda, R. P., Jahnel, M. and Wiltschko, R. (1999). Sun compass orientation in seed-caching corvids: its role in spatial memory. Animal Cognition 2, 215-221. 